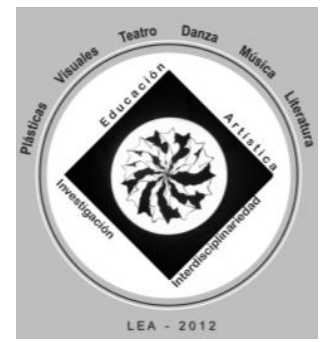

II ENCUENTRO NACIONAL

DE INVESTIGACIÓN, INTERDISCIPLINARIEDAD

Y EDUCACIÓN ARTÍSTICA

8 y 9 de noviembre de 2012.

Universidad Distrital Francisco José de Caldas

Bogotá, Colombia

\title{
Artes rituales y sagradas en: la ritualidad del ser
}

\author{
Por: Juan David Luján villar \\ Grupo de Investigación Literatura, Educación y Comunicación (LEC) Universidad Distrital \\ Francisco José de Caldas \\ lujanvillar@gmail.com
}

\begin{abstract}
Para que el alma pueda descansar, llegar a su sitio. Para que pueda llegar a su sitio, bueno esa se hace ese día, bueno ya se ha salió el alma del cuerpo, se elevó, ya la familia está tranquila porque llegó al sitio que le corresponde.
\end{abstract}

\section{Resumen}

El epígrafe anterior fue la respuesta del "profe" como se le conoce a Sebastián Salgado un miembro activo de la comunidad de San Basilio de Palenque al preguntarle por los lekos ${ }^{1}$ durante nuestro trabajo de campo (Sánchez y Luján, 2012: 77), esto se puede entender como un espacio fundamental en la práctica del ritual mortuorio del Lumbalú propio de esa comunidad de una clara raigambre africana. El presente trabajo se pregunta por el concepto de artes rituales y en un menor grado por las incertidumbres implícitas alrededor de la ritualidad del ejercicio artístico. Nuestra propuesta busca evidenciar líneas de trabajo investigativo, algunas reflexiones y ejercicios previos sobre la noción de ritual a partir de una apuesta transdisciplinar. Con el fin de realizar una conceptualización concerniente al ámbito de las artes sagradas, específicamente desde su dimensión performática -entendida como la dramatización, no solo como la puesta en escena vacía de significado- se presenta la siguiente investigación.

\footnotetext{
${ }^{1}$ Los lekos son una forma de gemidos o "gritos y voces guturales — son lamentos que combinan gritos estentóreos y ulular de voces donde se inserta el nombre del muerto. (...) al tiempo que se desenvuelve el rito de lecos, se inicia la preparación del cadáver" (Friedemann, 1992: 75-76; Sánchez y Luján, 2012: 77). Los estudios de Mazo (1994) adelantados sobre los lamentos fúnebres en algunas comunidades rusas sirvieron para proponer la hipótesis a nivel de respuestas cognitivas sobre la existencia de universales en aspectos del lamento como los gemidos, las exhalaciones, las exclamaciones excitadas, la respiración audible, la voz temblorosa, los jadeos, los sollozos y demás elementos paramusicales al lado de la descripción de sus diversos mecanismos, lo cual puede trascender las diferencias culturales.
} 


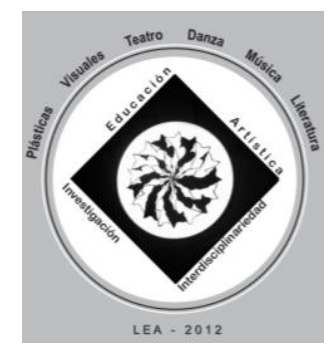

II ENCUENTRO NACIONAL

DE INVESTIGACIÓN, INTERDISCIPLINARIEDAD

Y EDUCACIÓN ARTÍSTICA

8 y 9 de noviembre de 2012.

Universidad Distrital Francisco José de Caldas

Bogotá, Colombia

Palabras clave: performatividad, artes rituales y sagradas, cosmocentrismo, creación, ser, ritual comunal, ritual común.

\section{Artes sagradas y adoracionales}

Machado (2011) en su trabajo de campo recogió un sin número de vectores sagrados ceremoniales sobre los indígenas Chocoes y Cuna (naciones Emberá y Waunana), situados en el Pacifico Colombiano. La investigadora exploró su vida religiosa y encontró en el ritual del Canto de Jai y su parafernalia, una serie de vectores morfológicos en sus bastones sagrados "un par de siameses" (Páchaidammeisa) que conectan su espiritualidad de manera cercana con el bastón igualmente sagrado (Mangki mesë) de la sociedad secreta Rö de los Wuli Mfunte, originarios de de Camerún (áfrica occidental). A esta hipótesis -basada en algunos relatos míticos Chocoes- se suma la increíble similitud con el concepto filosófico del Muntu existente en la misma área africana mencionada lo cual permite vislumbrar un paralelo que vincula y compara ambas expresiones escultóricas. La antropóloga relata que al llegar de la comunidad indígena donde reside el escultor Zuñigo Chamarra en su casa le dijo de manera concisa: "estoy aquí porque lo que me interesa es la memoria, lo que usted está recogiendo" (Machado, 2011: 47).

En la actualidad el complejo campo de la memoria colectiva y cultural está constantemente amenazado por un sinnúmero de permeabilidades las cuales a manera de armas para venderte algo son utilizadas por las mega-corporaciones y sus lógicas de mercadeo corporativo capitalista, lo cual por supuesto incluye la industria del arte mundial y su inmisericorde sed de dinero por encima de los sentidos socioculturales milenarios. Se hace necesario abrir la discusión en torno al cómo, esas memorias colectivas condensadas de manera ritual son además, patrimonios inmateriales y materiales que se relacionan con las posibilidades estéticas y argumentativas de distintos artistas, sus fases introspectivas y los procesos de creación tejidos a su alrededor. 


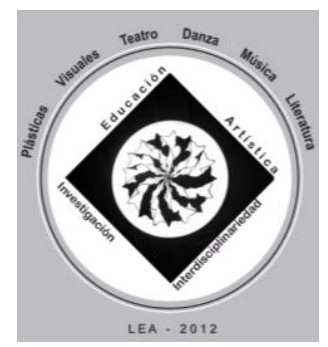

II ENCUENTRO NACIONAL

DE INVESTIGACIÓN, INTERDISCIPLINARIEDAD

Y EDUCACIÓN ARTÍSTICA

8 y 9 de noviembre de 2012.

Universidad Distrital Francisco José de Caldas

Bogotá, Colombia

\section{Definiciones y aspectos del concepto ritual}

Ana-Marie Losonczy (1992) brinda una definición del carácter situacional del concepto de ritual al sugerir éste como símil de repetición, aunque pudiera oscilar bajo probabilidades de improvisación, las características validadas en ambos tipos de actuaciones repetitivas e improvisadas se inscriben bajo sentidos prácticos provistos de eficacia:

La etimología latina del término «ritual», así como la concepción cristiana dominante del mismo, lo postulan como la repetición rigurosa de las palabras y gestos primordiales, repetición pensada como regla, normativa obligatoria, imposible de trasgredir. (...) El campo del chamanismo asiático y amerindio parece fundamentarse en una concepción de la eficacia ritual opuesta a la normatividad repetitiva, y muestra incluso en ciertas prácticas chamanicas un grado elevado de improvisación ritual. Lejos de que esta sea señal de una menor complejidad, aparece al contrario como parte fundamental de una cosmovisión original y compleja, parte de una estrategia intelectual de gran flexibilidad y adaptación al cambio (115).

A partir de lo anterior podemos acercarnos entonces a una definición tentativa del ritual, la cual sitúa el concepto de ritual dentro de un tiempo-espacial, una posible cronotopía inscrita en un plano lleno de heterosincronías. ${ }^{2}$ Esta configuración clasificaría el concepto ritual como inconcluso, abúndate en ambigüedades y desacuerdos, con una centralidad relevante en cuanto a su interpretatividad subjetiva y cuantioso en símbolos polisémicamente representativos, ya que son símbolos vivos y de origen cambiante. Díaz Cruz (2008: 35) recoge sobre los rituales, una condensación histórica y textual definida "ante todo (como) una forma donde se vierten contenidos, esto es; principios, valores, realidades, fines y significados constituidos de otro modo y en otro lugar, pero que los rituales expresan, para las miradas atentas, con relativa transparencia”.

Desde otra perspectiva el conocido antropólogo, genetista de poblaciones y promotor notorio de la vertiente teórica conocida como 'evolucionismo cultural' Luigi Cavalli Sforza (2007: 117) reflexiona los siguiente sobre el término ritual y su historia en las ciencias sociales:

\footnotetext{
${ }^{2}$ Para Cruces (1997: 55) las heterosincronías implican "la convivencia de temporalidades heterogéneas sobre un mismo espacio".
} 


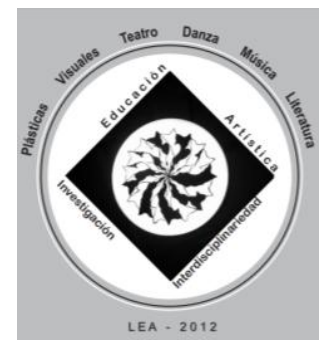

II ENCUENTRO NACIONAL

DE INVESTIGACIÓN, INTERDISCIPLINARIEDAD

Y EDUCACIÓN ARTÍSTICA

8 y 9 de noviembre de 2012.

Universidad Distrital Francisco José de Caldas

Bogotá, Colombia

La palabra «ritual» se refiere a una conducta altamente estandarizada y repetitiva, característica de uno o de muchos grupos sociales. El término hace referencia a un vasto conjunto de conductas que incluye los fenómenos de iniciación, todos los preceptos comunes a todas las religiones, cualquier rito y ceremonia de naturaleza sagrada o profana, y también los pequeños gestos repetidos que se convienen en obligatorios incluso para un único individuo. Fue Émile Durkheim quien identificó en el ritual la función de reforzar el sentido de pertenencia a un grupo social.

En este sentido, la cultura se evidencia como mecanismo de adaptación al medio tanto de los individuos como en los grupos sociales. Así, las innovaciones culturales traen consigo distintos factores que influyen en nuestra vida diaria además, presentan condicionamientos y formas de interactuar, y distintos beneficios distribuidos aún de manera desigual (Cavalli Sforza, 2007: 114). El proceso de comunicación está asimismo condicionado por el factor de la innovación el cual posiciona la cultura como un medio de difusión eficaz en sí. Se podría decir que entre coherencia cultural y las diferencias culturales todo indica que se que se definen los distintos grados de eficacia de la difusión cultural, debido a que los cambios y los vínculos sociales influyen gradualmente en lo que el mismo Cavalli Sforza define como transmisión cultural, esta perspectiva también incluye la adhesión al ritual y sus formas y por supuesto las actitudes rituales.

Durante mucho tiempo Victor Turner y su simbología comparativa fueron en antropología, referente clave en lo concerniente al ritual como práctica social y concepto, incluso él fue considerado durante varias décadas como "el antropólogo del ritual” (Reynoso, 2008: 54). Su aporte de alguna manera se puede delimitar desde la centralización en los símbolos y su estudio de la importancia y los modos de comprender, definir y clasificar el ritual en tanto conducta grupal. Después de analizar la estructura de los símbolos específicamente rituales de la sociedad Ndembu de Zambia se encontraron -según él-, aspectos tales como; multivocidad, unificación de significados dispersos, condensación, polarización de significados (polo ideológico o normativo y polo sensorial, fisiológico u oréctico). El ritual según su programa investigativo abarcaría desde la concepción de la vida ritual $^{3}$

\footnotetext{
${ }^{3}$ Roy Rappaport (2001: 526) recuerda a propósito del origen turneriano de algunos de sus planteamientos teóricos lo siguiente: "Durkheim nos proporciona la descripción de una fuerte experiencia numinosa originada
} 


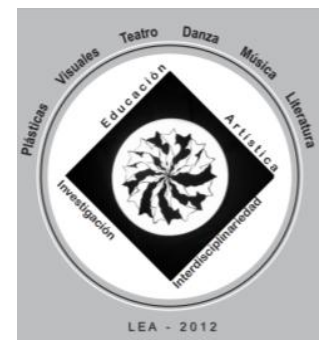

II ENCUENTRO NACIONAL

DE INVESTIGACIÓN, INTERDISCIPLINARIEDAD

Y EDUCACIÓN ARTÍSTICA

8 y 9 de noviembre de 2012.

Universidad Distrital Francisco José de Caldas

Bogotá, Colombia

etnografiáda del grupo poblacional Ndembu, hasta lo que denominó tres décadas después 'metáfora teatral' aplicada también a la vida ordinaria occidental. Respecto a la significación del símbolo, este sería la unidad mínima y es estructurada de acuerdo a una actitud y a un contexto, el del ritual propiamente tal. Las tres dimensiones de significados expuestas por Turner son; la dimensión posicional (de base nominal, sustancial y artefactual), una segunda dimensión exegética y una tercera dimensión operacional o performática (Reynoso, 2008: 54-55-56).

Tempranamente Turner ([1967] 1980) encontró que la posible deducción de las estructuras y propiedades de los símbolos rituales se podrían concluir basándose en tres clases de aspectos; "1) la forma externa y las características observables; 2) interpretaciones ofrecidas por los especialistas religiosos y; 3) contextos significativos ofrecidos por la antropología." Es importante recordar que el papel de su programa contribuye a una guía en términos operativos, aunque en general en sus trabajos no aparezca un orden establecido por el resultado de su metodología u ordenamiento y refinamiento analítico.

La antropóloga británica Mary Douglas reconocida por su fundamentación durkheimniana y su amplio trabajo sobre las distintas problemáticas venidas sobre el ritual como tema de estudio, plantea un debate interesante sobre el caso de la palabra ritual y su uso, según ella indiscriminado en las sociedades occidentales. Douglas escribe al respecto:

en lo que Victor Turner, medio siglo después (1969), denominó communitas; experiencia que (...), tiene probabilidades de generarse en el ritual comunitario." Durkheim famoso por definir sus conceptos en el sentido ritual desde lo que diríamos a grandes rasgos como factores objetivos entre sociedad y cultura. Sobre la vida religiosa de lo que Durkheim y gran parte de los pensadores de su época denominaban 'pueblos primitivos' en un sentido estricto, encuentra lo que señala como una variada y amplia, gama de 'actitudes rituales', estos y otros aspectos de su obra en el sentido del ritual como campo de cohesión social se pueden ver en Durkheim (1968: 311). La noción de communitas es discutida en profundidad por Reynoso (2008: 58) quién escribe al respecto; "la communitas es una relación entre individuos concretos, históricos y con una idiosincracia determinada, que no están segmentados en roles y status sino enfrentados con el resto de la sociedad o separados de ella. La communitas es espontánea e inmediata, pero también tiende a cristalizarse y a desarrollar una estructura. (...) La communitas se manifiesta de diversas maneras: (...) Communitas existencial o espontánea, más o menos lo que los hippies llamarían un happening. (...) Communitas normativa, que bajo la necesidad de organizar sus recursos a la larga se transforma en un sistema social duradero. (...) Communitas ideológica, que se puede aplicar a diversos modos utópicos de sociedades basadas en la comunidad existencial". 
En lugar de lanzarse al anti-ritualismo, sería más práctico experimentar con formas institucionales más flexibles tratando de cultivar la expresión ritual que las caracterice. Pero esto significaría salir abiertamente al mundo, mezclarse con la corrupción y el pecado, ensuciarse las manos con las formas de lo externo, dialogar con las formas despreciadas, en lugar de adorar los sagrados misterios de la pureza del cero (1988: 186).

El estudio del ritual en tanto representación social es sostenido por Douglas (1988) fundamentalmente bajo una noción del análisis de la vida ordinaria y sus hechos anodinos: "Esto nos lleva a la teoría de Durkheim según la cual la experiencia compartida por la sociedad estructura la conciencia del individuo ajustándola a la de la colectividad" (1988: 179). Se puede considerar a Douglas como una antropóloga simbolista, aunque teóricamente bajo una óptica diferente a la de Turner. Su simbología -la cual en sus textos maduros reniega del 'funcionalismo' - en el sentido del ritual y su estudio propuso el modelo conocido como 'cuadricula y grupo' (1988: capítulo cuatro) el cual está basado en los conceptos de código restringido y código elaborado. Su análisis a grandes rasgos, se puede sintetizar de la siguiente manera; “donde la solidaridad del grupo es mayor, hay más ritualización y más códigos restringidos; donde la solidaridad es menor, hay una mayor secularización y más códigos elaborados” (Reynoso, 2008: 74). ${ }^{4}$

La historia funcionalista del ritual como enfoque de estudio en sociología -en el seno de las vidas religiosas- es vertido en contra de los legados de la ilustración y su pensamiento heredado en las ciencias sociales. El ritual por lo tanto, se localizó en la reacción de la sociología conservadora como un aspecto respetable y digno de disertación aunque no fuese

\footnotetext{
${ }^{4}$ Una excelente crítica sobre el trabajo de Mary Douglas así como de su historia, despliegue, aspectos importantes y demás opiniones se encuentra en Reynoso (2008) quién recuerda como Douglas basada en los conceptos del sociolingüista Basil Bernstein 'código restringido' y 'código elaborado', lleva estas dos categorías lingüísticas a situarlas también como sociológicas: "El código restringido surge en situaciones sociales en pequeña escala, en la que todos los hablantes tienen acceso a los mismos supuestos fundamentales, y en la que todas las expresiones están puestas al servicio del orden social. Estos códigos utilizan un fondo léxico más pequeño y una sintaxis más rígida y más simple. Lo que se dice en base a ellos tiene carácter general y es conocido por todos. Por lo común es tan conciso que resulta indescifrable si no se conocen los supuestos. (...) El código elaborado se aplica a las situaciones sociales en las que los hablantes no aceptan o no conocen necesariamente los supuestos de sus interlocutores. Estos códigos tienen una base léxica más grande y mayores posibilidades de articulación sintáctica. En su forma extrema, el código elaborado está tan desligado de la estructura social que puede incluso llegar a anularla y a hacer que el grupo social se estructure en torno al habla, como ocurre en el caso de una conferencia pronunciada en un aula universitaria." (Reynoso, 2008: 74).
} 


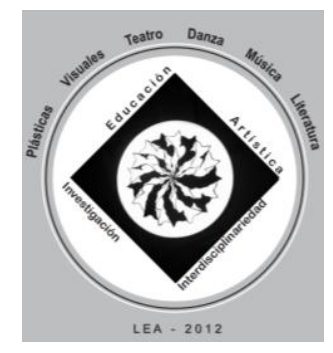

II ENCUENTRO NACIONAL DE INVESTIGACIÓN, INTERDISCIPLINARIEDAD

Y EDUCACIÓN ARTÍSTICA

8 y 9 de noviembre de 2012.

Universidad Distrital Francisco José de Caldas

Bogotá, Colombia

considerado como estrictamente racional por los estudiosos pertenecientes a la teoría sociológica clásica y su posterior desarrollo. Sobre este particular Ritzer (1993) recuerda los diez puntos que lrving Zeitlin -uno de los grandes investigadores de la historia de la sociología y la religión- define sobre las características de dicho periodo fundacional en la historia sociológica. Uno de estos puntos atañe estrictamente a lo relacionado con la importancia de la vida ritual y religiosa: "Aunque gran parte de estos temidos cambios daba lugar a una sociedad más racional, la reacción conservadora llevaba a reconocer la importancia de (...) factores no racionales (por ejemplo, el ritual, la ceremonia y el culto) de la vida social." (Ritzer, 1993: 14). Esto explica de modo simple por qué en la teoría social contemporánea la noción de ritual no posea la fuerza histórica que el concepto lleva consigo mismo en las ciencias sociales. Ahora bien, más que un concepto para nosotros la ritualidad de los seres humanos es un campo de acción investigativa susceptible de ser abordado de manera transdisciplinar.

\section{Creación ritual y desarrollo del ser}

Un primer acercamiento al arte y lo estético en tanto necesidad de desarrollo del ser y justificación de su ritualidad, se presenta como una necesidad atravesada por la performatividad del accionar social, de acuerdo a las convergentes visiones de mundo que éste percibe. Para comprender una parte fundamental del ritual y la necesidad de esta dimensión en la vida social humana retomamos su importancia en tanto creación, como una posible categoría axiológica o valorativa en una sociedad determinada. Manfred Max- Neef ([1993] 1998) en su texto desarrollo a escala humana contempla cuatro dimensiones sobre la condición humana, sus necesidades y satisfactores, en relación con el panorama de la creación propia del sujeto; ser, hacer tener y estar, las cuales serían de modo fundamental categorías existenciales. 


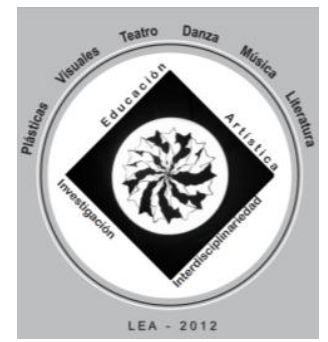

II ENCUENTRO NACIONAL

DE INVESTIGACIÓN, INTERDISCIPLINARIEDAD

Y EDUCACIÓN ARTÍSTICA

8 y 9 de noviembre de 2012.

Universidad Distrital Francisco José de Caldas

Bogotá, Colombia

Tabla 1. Matriz de necesidades Max- Neef

\begin{tabular}{|l|l|l|l|l|}
\hline \multicolumn{1}{|c|}{ Ser } & \multicolumn{1}{c|}{ Tener } & \multicolumn{1}{c|}{ Hacer } & \multicolumn{1}{c|}{ Estar } \\
\hline Creación & $\begin{array}{l}\text { Pasión, voluntad, } \\
\text { intuición, imaginación, } \\
\text { audacia, racionalidad, } \\
\text { autonomía, inventiva, } \\
\text { curiosidad. }\end{array}$ & $\begin{array}{l}\text { Habilidades, } \\
\text { destrezas, } \\
\text { métodos, } \\
\text { trabajo. }\end{array}$ & $\begin{array}{l}\text { Trabajar, inventar, } \\
\text { construir, idear, } \\
\text { componer, diseñar, } \\
\text { interpretar. }\end{array}$ & $\begin{array}{l}\text { Ámbito de producción y } \\
\text { retroalimentación, } \\
\text { talleres, audiencias, } \\
\text { ámbitos de expresión } \\
\text { libertad temporal. }\end{array}$ \\
\hline
\end{tabular}

Fuente: Max- Neef, et. al (1998: 59).

Consideramos que es en el marco de esta serie de factores primordiales para el desarrollo humano que el concepto de creación se considera trascendente, no solo sobre el bienestar sopesado en bienes económicos (objetos y artefactos), sino en el sentido de potenciar el bienestar humano a través de la identificación de satisfactores del ser y, no necesariamente bienes materiales, aunque éstos se presenten como productos consecuentes de la obtención plena de los satisfactores obtenidos. No obstante, como sugieren los autores sobre el cuadro anterior éste también puede modificarse en cuanto a sus categorías existenciales, según lo disponga cada sujeto o conjunto poblacional que posea características culturales y cosmovisiones específicas. Por lo tanto, la creación cubre gran parte de la inventiva social e introspectiva de la vida humana en su dimensión ritual y el desarrollo del ser.

\section{Cosmocentrismo y autorreferencia local}

Cuando Marx planteaba que "la religión es el opio del pueblo" esbozaba que la dominación del vínculo iglesia y el poder estatal (anticlericalismo) ejercían de manera económica sobre las personas un adoctrinamiento irrefutable y un acondicionamiento inimaginable de acuerdo al cambio social. No obstante como especula Amín (2006) tal nihilismo direccionado desde Occidente, durante los siglos XIX y XX no fue suficiente para apartar al hombre de su -al parecer infinita-, búsqueda metafísica desde que éste tuvo consciencia y comprensión de su espacio habitacional el cual fue jerarquizado. El humano (mujeres y hombres) entonces, es por excelencia un "animal metafísico" (Amin, 2006) en definitiva, un consumidor constante de ese "opio" del cuál hablada Marx. 


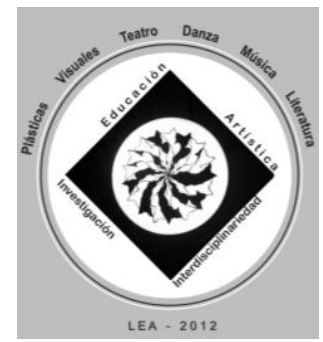

II ENCUENTRO NACIONAL

DE INVESTIGACIÓN, INTERDISCIPLINARIEDAD

Y EDUCACIÓN ARTÍSTICA

8 y 9 de noviembre de 2012.

Universidad Distrital Francisco José de Caldas

Bogotá, Colombia

La explicación que brinda Walter Rodney ([1972] 1982) -quien se distinguió por ser un materialista histórico consumado- nos sirve como argumento de lo anterior. El investigador guyanés sugiere que; "la religión es un elemento de la supraestructura de la sociedad, derivado, en última instancia, de un grado de control y comprensión del mundo material" (47). Si bien el sentido de la religión puede ser negativo o positivo, la forma y resistencia cultural del ritual sagrado, es política en sí, particularmente en comunidades que se resisten a las locomotoras desarrollistas y su ejecución del progreso materialistamente centralizado, al conservar posturas bioéticas y de resistencia frente a la conservación de sus territorios en muchas ocasiones sagrados. ${ }^{5}$ En consecuencia, el no-absolutismo religioso acompañado de una posición cosmológica abre la posibilidad de deslegitimar las lógicas occidentales de “control cultural” y acrecentamiento paraétnico en sus distintas versiones etnocéntricas. Es una opción de posicionamiento alternativo de relacionamiento frente a las múltiples problemáticas del mundo al comprender en la práctica por ejemplo, la naturaleza tan sólo no como objeto. La evidente mercantilización del mundo propia del modelo capitalista, entonces es suprimida dando paso a políticas y posturas bioéticas, ecologías de lo sacro, lo cual tiene hacedero en lo ritual sagrado que cada comunidad étnica determina en tanto posicionamiento territorial.

Carvalho (2011) describió sobre su trabajo la economía de Axe como una hermosa forma organizada de cómo las comunidades de los pueblo tradicionales de terreiros (patios o solares) son contendores de religiosidades afroamericanas situadas en las áreas urbanas de Belém / PA, Recife / PE, Belo Horizonte / MG y Porto Alegre / RS, perviven con lo que él denomina una economía que gira entorno a la red terreiros o pueblo del santo. El pueblo del santo o gente del Axe mantiene una larga historia económica tejida alrededor de lo ritual de matriz africana. Es así, como el investigador sistematizó su secuencialidad y prácticas

\footnotetext{
${ }^{5}$ Algunos ejemplos etnográficos pueden ilustrar este punto. Arocha (2005) anota acerca del ritual de "la ombligada", cómo una colega suya, es sorprendida por el dolor de un "mayoritario" en la comunidad afro en Timbiquí (Enero, 2004) "cuando unos paisas que propagan la coca talaron el bosquecito que albergaba los ombligos de su papá y su mamá, y donde él cada día hablaba con las almas de ellos” (Febrero 27).

${ }^{6}$ Mis sinceros agradecimientos al profesor Jaime Arocha por su amable invitación a esta sesión de trabajo. En la misma medida al profesor José Jorge de Carvalho por el interés en nuestra investigación sobre el ritual del Lumbalú y sus valiosas sugerencias.
} 


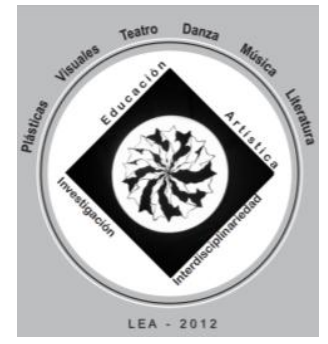

II ENCUENTRO NACIONAL

DE INVESTIGACIÓN, INTERDISCIPLINARIEDAD

Y EDUCACIÓN ARTÍSTICA

8 y 9 de noviembre de 2012.

Universidad Distrital Francisco José de Caldas

Bogotá, Colombia

sociales al evidenciar labores, servicios, artes y profesiones las cuales originan productos alimenticios, medicinales, además de la crianza de animales sanos para el consumo humano a través de procesos de producción comunitarios. Todo esto ligado inherentemente con la creencia cosmocéntrica en la religión yoruba-afrobrasileña. Las fundamentaciones de esta cosmología se presentan en la misma ritualidad que la comprende. Esta visión rescata la cosmovisión de su arte definida por Carvalho (2011) como una ecología sagrada mediada por la invocación espiritual, la cual resiste a los modelos foráneos de desarrollo ideologizantes y a los múltiples racismos que perviven en las Américas, en el sentido de procurar "entregar lo mejor" para sus propias poblaciones para este caso el pueblo de los santos, al igual que en los encuentros rituales y adoracionales con tales deidades.

Esta autorreferencia de los terrerios de inspiración cosmocéntrica establece un claro ejemplo no solo para la sociedad brasileña, sino también para el resto del mundo latinoamericano, como alternativa a posibles crisis alimentarias y socioeconómicas. Su valor reside entonces, en que lo local en esta experiencia compartida rescata la ritualidad que comprende su mundo espiritual de manera espacial, en relación con el mundo moderno y transnacionalmente globalizado como resultado homogéneo. Al rescatar la memoria ritual, ceremonial y por supuesto artístico-estética de raigambre ancestral recogida por los mayores o sabios de dichas comunidades, se configura un espacio ritual significativo como mínimo en dos dimensiones, como veremos a continuación.

\section{Ritual comunal y ritual común}

El acercamiento al concepto de ritual en la etapa clásica de las ciencias sociales fue presentado por lo general en términos ceremoniales, pero en tanto producto de distintos procesos del pensamiento humano no se establece en una dirección unilateral o a un solo escenario y al parecer tampoco se organiza de forma estructural, ya que se vislumbra como producto de los cambios y las transiciones generacionales, lo cual dificulta su estudio debido al problema de captación de su proceso de sistematización logocéntrico (escritural), y esto último puede llegar a ser un ejercicio riesgoso de reducción experiencial. Para 


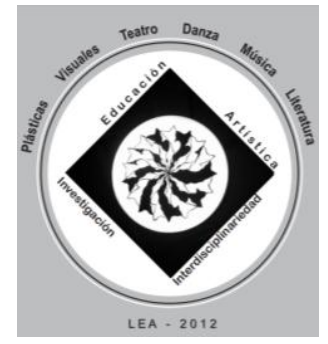

II ENCUENTRO NACIONAL

DE INVESTIGACIÓN, INTERDISCIPLINARIEDAD

Y EDUCACIÓN ARTÍSTICA

8 y 9 de noviembre de 2012.

Universidad Distrital Francisco José de Caldas

Bogotá, Colombia

establecer la diferencia entre el ritual comunal y lo ritual debemos establecer su diferencia en el sentido de su abordaje, lo cual radica por lo menos en reconocer dos características de ambas etapas:

1. El ritual vislumbra la forma escenificada y performatica de la elaboración interpretativa de diversos grados de espiritualidad y trance, y debe ser comprendido por fuera de la simplicidad con la cual de manera liviana el comentario cultural descriptivo sitúa tal performatividad en el trabajo de campo (Trouillot, 2011: 233). En un caso cultural preciso que ilustra este punto Díaz (2008: 34) explica que “entre los Avá-Chiripá del Paraguay, solo es posible apropiarse del valor y significado de un sueño cuando se le dramatiza en forma ritual." Por lo tanto, el desarrollo ritual a nivel comunitario permite que:

A través de la dramatización del sueño los Avá-Chiripá están creando, en ese espacio y tiempo performativo, la presencia sobrecogedora de lo sagrado, están transfigurando al soñador en shamán, pues queda claro que no cualquiera sueña en la visita de unos mensajeros divinos que donan cantos y recitaciones con poderes curativos (Díaz, 2008: 39).

2. Lo ritual por el contrario, se desliga de sus momentos de ejecución práctica y definición conceptual al tener como dificultad la delimitación de los aspectos que componen la experiencia ritual. Tal experiencia, históricamente se presenta teñida bajo la tinta del reportaje realista y la recolección del material etnográfico primario amparado exclusivamente en el enfoque descriptivo y cercano a lo que Trouillot (2011: 187) denominó "trilogía etnográfica: un observador, un tiempo, un lugar." Para nosotros lo ritual es comprendido bajo una serie de proyecciones e interiorizaciones experimentadas por todo el ser del participante, no solo de modo cognitivo. Si partimos de la secuencialidad generalizada en el concepto ritual de etimología latina (rítus), el cual significa repetición según explica Losonczy (1992: 115) lo ritual no sería necesariamente comunal ya que se podría amparar en la subjetividad de la experiencia performatica y su intimidad (un espacio y tiempo performativo). Así, el ritual y lo ritual son dos fases de un mismo proceso 


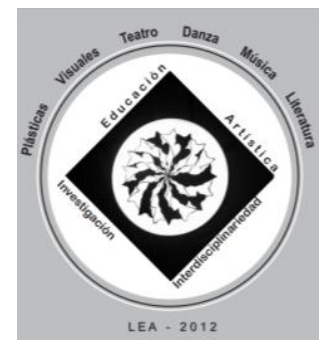

II ENCUENTRO NACIONAL

DE INVESTIGACIÓN, INTERDISCIPLINARIEDAD

Y EDUCACIÓN ARTÍSTICA

8 y 9 de noviembre de 2012.

Universidad Distrital Francisco José de Caldas

Bogotá, Colombia

pero no son lo mismo. Esta última fase se define mejor como un corpus ritual y

no solo como un culto a algo o a alguien específico.

A partir de lo anterior proponemos considerar la doble posibilidad del ritual en la práctica comunal como un vector que nos lleva en retrospectiva a los primeros sistemas de distribución de la tierra y organización social, es decir un comunalismo pre-feudal. Seguidamente entendemos la comprensión del ritual como ejercicio común el cual puede ser comunal o no. Para explicar esta dualidad consideremos algunos ejercicios que en la práctica son anodinos en algunas sociedades además equivalentes a intricados procesos de sociabilidad. Tomemos dos ejemplos para dilucidar esta cuestión. Sánchez y Luján (2012) realizaron sobre la funeraria de San Basilio de Palenque y su particular forma de despedir a los muertos de esta comunidad un análisis estético del denominado ritual de Lumbalú. En esta exploración se evidenciaron los códigos y procesos estéticos que giran a través de este transcurso mortuorio, manifiestos en sus artes rituales y sagradas las cuales son guiadas mediante su lenguaje criollo $^{7}$ una mezcla entre español, portugués, con fuertes rasgos originarios de la nación Bantú ${ }^{8}$ de la raíz lingüística Ki-kongo probablemente del pueblo Vili de Loango en Angola (Maya, 2010: 120; Friedemann, 1991: 68; Sánchez y Luján, 2012: 25). Este ritual contiene pilares estéticos que son precisamente comunales; musicalización, simbología, culinaria y planimetría, lo cual por ser de esta manera posee niveles de consenso, así como unas bases y tiempos específicos para su realización. El Lumbalú se puede considerar como un proceso social integrado, y no precisamente aislado de la realidad en tanto hecho íntimamente doloroso. La comprobación de la doble posibilidad ritual yace en que es tanto comunal como común es decir, es un ritual íntimo pero participativo en un nivel étnico (Sánchez y Luján, 2012).

El segundo ejemplo aunque no se contrapone a la teoría tradicional de ritual $-\mathrm{y}$ su sentido colectivo, ya sea a nivel de pensamiento, territorial, lingüístico o étnico- es propuesto sobre

\footnotetext{
${ }^{7}$ Conocida como lengua Palenquera, actualmente se encuentra en el inmenso repertorio de las lenguas étnicas en peligro de extinguirse (Oquendo, 2012, Mayo 22).

${ }^{8}$ Para una revisión del lenguaje Bantú en Cuba ver Schwegler (2002a) y sobre los orígenes lingüísticos de Palenque de San Basilio ver Schwegler (2002b).
} 


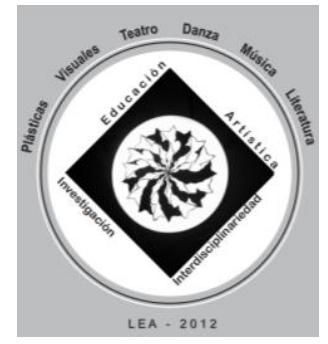

II ENCUENTRO NACIONAL

DE INVESTIGACIÓN, INTERDISCIPLINARIEDAD

Y EDUCACIÓN ARTÍSTICA

8 y 9 de noviembre de 2012.

Universidad Distrital Francisco José de Caldas

Bogotá, Colombia

la ritualidad del arte o lo ritual de la performatividad del artista, como parte fundamental de su ser. ${ }^{9}$ Este aspecto se presenta en la preparación de la obra artística como una constante en los procesos de creación. Desde la primera idea reflexiva tejida alrededor del misterio que encierra la concepción de la obra (Laignelet, 2007) hasta la recepción cognitiva y discursiva, lo ritual continúa de manera intrínseca en los procesos expresivos mediados por el artista y acompaña el despliegue de la obra de arte apreciada por el entendimiento del ser humano perceptivo.

Esta etapa que comienza en la disposición sensorial de transmitir y recibir una idea se observa inclusive en los deportistas de alto rendimiento, los cuales a manera de ritual elaboran su rigurosa preparación psicomotriz. Es así, cómo el ritual común comprende la levedad de los hechos anodinos, construcciones de la sociabilidad o patrones estéticos relacionales en los cuales se moldean los vínculos humanos. La posibilidad de asombro de la experiencia estética que sentimos es aquello que se establece en nuestra conciencia a través de la sensación y experimentación de lo artístico, lo cual conjuga y sobrepasa el objeto percibido y su concepto representacional. A este tiempo-espacio lo denominamos; la dimensión ritual de la obra de arte es decir, la complejización de la observación reflexiva y la introspección cognitiva de la experiencia corporeizada.

\section{¿Arquitectura y tecnología ritual?}

Ferreira (2012) etnomusicólogo y músico propone sobre las músicas afroamericanas unas pautas para comprender sus cimientos performáticos los cuales encuentran hacedero en la propuesta de una posible arquitectura del ritual, en tanto complejo performatico. ${ }^{10} \mathrm{La}$

\footnotetext{
${ }^{9}$ Esta dimensión no es comprendida de modo exclusivo sobre aquellos profesionales denominados artistas avalados por las instituciones académicos, en su lugar denominamos artistas a seres que haciendo uso de su expresividad en el marco de su subjetividad y contexto social, en cualquiera que sea su entorno habitacional desarrollan actividades de acuerdo a las diversas posibilidades artísticas que disponen.

10 Agradezco las amables y detalladas explicaciones del profesor Ferreira quien realizó un esfuerzo, por dilucidar mis -casi siempre- extrañas dudas en el marco del seminario-taller "Músicas afrolatinoamericanas" temas y problemáticas en los estudios sobre las músicas de matrices africanas en Latinoamérica y el Caribe. Organizado por el Departamento de Música de la Facultada de Artes de la Pontificia Universidad Javeriana y el Centro de Documentación Musical.
} 


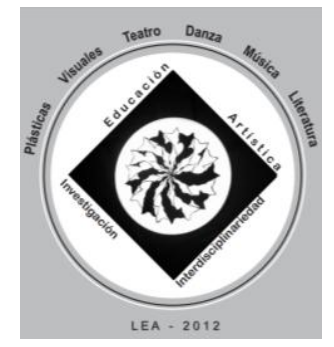

II ENCUENTRO NACIONAL

DE INVESTIGACIÓN, INTERDISCIPLINARIEDAD

Y EDUCACIÓN ARTÍSTICA

8 y 9 de noviembre de 2012.

Universidad Distrital Francisco José de Caldas

Bogotá, Colombia

secuencialidad presentada a continuación es considerada por nosotros como un engranaje alrededor del conocimiento de lo ritual esto es, una tecnología ritual:

1. La emergencia de un patrón secuencial.

2. La localización de una microestructura.

3. Una estructura performática.

4. Y un corpus ritual.

La emergencia de un patrón secuencial, edifica la arquitectura ritual, ya sea de repetición, de significación o de un leguaje simbólico imaginado sobre la imbricación de los tres aspectos restantes. La localización de una microestructura, se establece a partir de un proceso cognitivo alrededor de un entramado epistémico específico, por lo general de carácter adorativo. Esta microestructura define grados de improvisación y fijeza ritual (marcos y márgenes rituales) con la finalidad de llegar a establecer una estructura performatica o sea, una afirmación corporeizada a través de la dramatización ${ }^{11}$ de lo que ocurre en el curso de la actividad performática. Estos cuatro aspectos generan un engranaje anudado al complejo simbólico comunal del contexto cultural desde la puesta en escena que incluye un acumulado para llegar a un corpus ritual. En síntesis, el conocimiento ritual y su plano tecnológico son una forma de textualidad cultural análoga característica, establecida en pro de unos 'aspectos distintivos del propio ritual' (Rappaport, 2001: 65; Díaz Cruz, 2008: 36).

\section{Elaboraciones de lo ritual y su desritualización: el simbolismo espacial}

Es innegable que muchas de las manifestaciones de orden artístico y performatico se establecieron a través complicados procesos que fueron de modo inicial de origen ceremonial y ritual hasta llegar de modo gradual al vaciamiento simbólico presente de su aura mística y sacra originaria. Como plantea Rodney ([1972] 1982: 46) con base en el ya clásico materialismo histórico sobre en el continente africano; "la música y la danza

\footnotetext{
${ }^{11}$ Por dramatización se entiende desde Turner, un momento comunal en el cual la acción performática forma parte de un contexto situacional establecido, en el cuál los actores del drama se entregan a la espiritualidad que en un momento tal (el cual puede ser diacrónico) se manifiesta en una conducta ritual.
} 


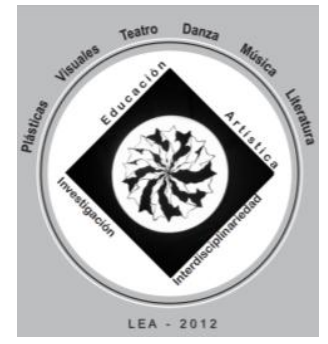

II ENCUENTRO NACIONAL

DE INVESTIGACIÓN, INTERDISCIPLINARIEDAD

Y EDUCACIÓN ARTÍSTICA

8 y 9 de noviembre de 2012.

Universidad Distrital Francisco José de Caldas

Bogotá, Colombia

desempeñaron un papel clave en lo que podría llamarse la sociedad africana original o "no contaminada." Aspectos similares son presentados en dos casos de la población del afropacífico colombiano descendientes sobre esas africanidades inicialmente no contaminadas. Arboleda (2011) problematiza - con base en el estudio del legendario Teófilo Roberto Potes y su legado-, sobre la elaboración actual de los instrumentos de música tradicional del complejo afropacífico. Recuerda que sus sentidos anteriores o ancestrales llegaron hasta el actual momento a partir de rituales, ceremonias y cosmologías que fueron alteradas debido a un sin número de factores de riesgo de la sociedad moderna. El autor explica la relación entre la construcción de un instrumento musical y la ritualidad desplegada en torno a este proceso:

La construcción en este caso de la marimba ${ }^{12}$ tenía su centro de elaboración en los ciclos naturales de las mareas y por lo tanto las lunas, ello determinaba el corte de las chontas, las guaduas, bejucos y demás materiales para garantizar un sonido que conmoviera la estructura humana y convocara su sensibilidad. Al igual que el cununo llamador con el fino respeto que envuelve a la mujer en su etapa de virginidad, sólo ella podía ayudar a elaborarlo en un complejo ritual de iniciación. (...) Los instrumentos musicales en esta perspectiva son iconos de memoria histórica y referente de un profundo conocimiento del funcionamiento de los ecosistemas de donde se obtienen dichos materiales. Todo induce al cuidado y a la armonía entre seres humanos y naturaleza (Arboleda, 2011: 344).

Esta perspectiva nos lleva al segundo caso, abrir el debate sobre la orientación cosmológica y metafísica en la construcción de lo ritual y su actual desritualizacion, a propósito de la performancia entrelazada comunalmente respecto a lo sonoro y lo danzario, en la misma región afropacífica colombiana. Gran parte de las ciencias humanas y sociales identifican el espacio ritual como un espacio comunitario de interacción de un valioso poder comunicativo y cognitivo (Blacking, 1976; Blacking y Kealiinohomoku, 1979; Losonczy, 1992; Miller, 2000; Turner, 1969; 1988). No obstante, la actual forma de concebir 'lo sagrado' y 'lo espiritual' se presenta dentro de contextos 'espectaculares' alejado de su

\footnotetext{
${ }^{12}$ El recuento que elabora Miñana Blasco (2010: 330) en su análisis sobre la afinación de las marimbas de chonta colombo-ecuatorianas, sirve para ampliar el sentido afrodiasporico propuesto en este espacio ya que al cruzar el sentido performatico de la ejecución de este instrumento su historia también coincide con otras sitios de la región latinoamericana: "En Brasil hay documentación histórica, iconográfica y etnográfica del uso de la marimba por los negros desde el siglo XVIII, pero ha ido en desuso; estuvo asociado hasta la década de 1950 al acompañamiento de algunas danzas dramáticas (ritualizadas) como la congada" (el énfasis es nuestro).
} 


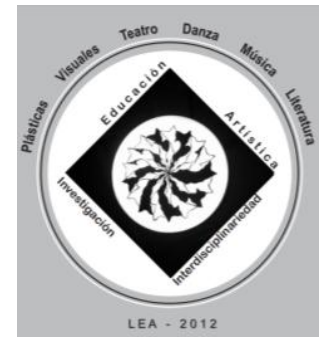

II ENCUENTRO NACIONAL

DE INVESTIGACIÓN, INTERDISCIPLINARIEDAD

Y EDUCACIÓN ARTÍSTICA

8 y 9 de noviembre de 2012.

Universidad Distrital Francisco José de Caldas

Bogotá, Colombia

sentido central, aquello que las mismas comunidades llaman lo nuestro, aquellas expresiones vernaculares.

Las propias poblaciones deben de concebir desde el interior es decir, en sus comunidades de base y a partir de sus valores culturales ¿Cómo y cuál son las interiorizaciones en sus prestaciones identitarias?, ¿Cuál sería el despliegue propicio de su “control cultural”? (Bonfil Batalla, 1992), sobre lo cual Carvalho (2002) denomina "lo negociable e innegociable" Pero también sugiere a los artistas contemporáneos, encaminados por estos senderos y concepciones de trabajo artístico, asumir una posición política entorno a su filosofía de trabajo y expresión creativa mediante el compromiso social frente a problemáticas actuales relacionadas con comunidades, etnias, territorios y patrimonios inmateriales.

Es en relación al "significado en términos de organización del simbolismo espacial, de las relaciones, de las jerarquías sociales o de los papeles rituales" (Barañano et.al. 2003) mediados por las artes, que las circunstancias de nuestro tiempo demandan, una fuerte reconstrucción y contestación a la filosofía históricamente anclada a una monocultura occidental englobante y estetizante.

\section{Algunas conclusiones}

Con la salvedad, añadiría yo, de que, en materia de religión, al igual que sucede con el arte, no hay pueblos «más sencillos», sino sólo algunos pueblos con tecnologías más sencillas que la nuestra. La vida «imaginativa» $\mathrm{y}$ «emotiva» del hombre es, en todo lugar y ocasión, rica y compleja. (...) Tampoco es del todo exacto hablar de la «estructura de una mente distinta de la nuestra»; no se trata de estructuras cognitivas diferentes, sino de una misma estructura cognitiva que articula experiencias culturales muy diversas (Turner, 1988: 15).

Esta exposición intentó demostrar cómo el despliegue de la voz investigativa propuesta para las artes de tipo ritual y participativo crea una la necesidad de considerar los aspectos rituales y su simbología espacial circudante como una muestra de pervivencia tanto de las 


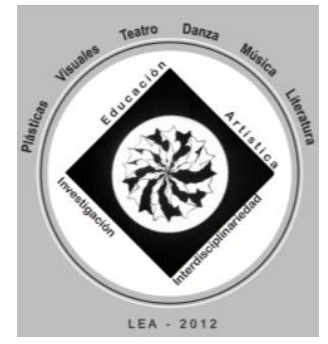

II ENCUENTRO NACIONAL

DE INVESTIGACIÓN, INTERDISCIPLINARIEDAD

Y EDUCACIÓN ARTÍSTICA

8 y 9 de noviembre de 2012.

Universidad Distrital Francisco José de Caldas

Bogotá, Colombia

formas de vida seculares como de los lugares anodinos. Más que una conceptualización aislada que tiene como fin su intervención próxima, existe la necesidad de investigar en las artes rituales y sagradas, la ritualidad del ser. Se hace necesario entonces, pensar parafraseando a Hall (1992) ¿Qué momento es este? respecto al ritual y el performance de carácter étnico dentro del imaginario del mundo del arte y las practicas anodinas en los espacios sociales e individuales? En definitiva este momento no se presenta en blanco y negro, recordemos que es profundo el efecto que produce en nuestras vidas en el presente la colonización, la asimilación cultural foránea y aculturación recibida por parte de los mass media, el neocolonialismo, las políticas de la multiculturalidad y su avasallante envestida liderada por el neoliberalismo y la violencia epistémica doméstica que configuran un presente histórico escuálido en termino étnicos y vacío de significados sustanciales para el común de muchos sujetos latinoamericanos. Como vemos es algo más que complicado.

Surgen algunos interrogantes de orden metodológico: ¿Qué tipo de visibilización es la que los actores rituales (performers) quieren de ellos mismos? ¿Cuál queremos de ellos? y ¿Cuál queremos de nosotros? Creemos que en el campo de los escenarios rituales y demás performancias ritualizadas existe un margen considerable de aciertos y desaciertos sobre los encuadres epistemológicos de estos lugares. Tales problemáticas sugieren apuestas de indagación ingeniosas, que amplíen el espectro universalista y facilista respecto al abordaje insensible de las temáticas rituales. El epígrafe anterior escrito por Turner (1988) hace más de cuarenta años resume de modo general la perspectiva investigativa que tratamos de esbozar en este espacio, la cual encuentra en las artes sagradas, lo ritual y el ser humano un campo de exploración epistemológica trascendental.

\section{Bibliografía}

Amin, Samir (2006). De la crítica del racialismo a la crítica del euroccdentalismo cultural. En Césaire, Áime. (2006). Discurso sobre el colonialismo. Madrid: Ediciones Akal.

Arboleda, Quiñonez, Santiago (2011). Le han Florecido Nuevas Estrellas al Cielo: Suficiencias íntimas y Clandestinización del Pensamiento Afrocolombiano (Tesis de Doctorado). Universidad Andina Simón Bolívar Ecuador, Santiago de Cali. 


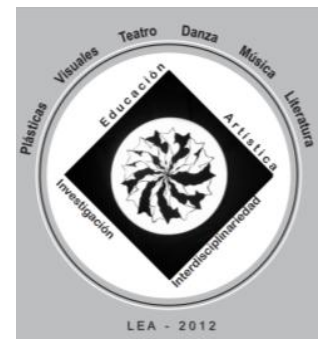

II ENCUENTRO NACIONAL

DE INVESTIGACIÓN, INTERDISCIPLINARIEDAD

Y EDUCACIÓN ARTÍSTICA

8 y 9 de noviembre de 2012.

Universidad Distrital Francisco José de Caldas

Bogotá, Colombia

Arocha, Jaime (2005, Febrero 27). Desterrar afrocolombianos para patentar chontaduros. UN periódico, 7.

Barañano, Ascensión, Martí, Josep, Abril, Gonzalo, Cruces, Franciso y Carvalho, Jose Jorge de (2003). World Music, ¿El folklore de la globalización? En Revista Transcultural de Música. Transcultural Music Review (7). Recuperado de http://www.metro.inter.edu/facultad/esthumanisticos/ceimp/articles/World\%20Musi c\%20El\%20folklore\%20de\%20la\%20globalizacion.pdf [consultado Enero $10 \mathrm{de}$ 2012]

Blacking, John (1976). How Musical Is Man? London: Faber and Faber.

Blacking, John y Joann W. Kealiinohomoku (Eds.) (1979). The Performing Arts: Music and Dance (pp. 205-219). The Hague: Mouton. https://doi.org/10.1515/9783110800692

Bonfil, Batalla, Guillermo (1992). Identidad y pluralismo cultural en América Latina. San Juan: Fondo Editorial del CEHASS, Editorial de la Universidad de Puerto Rico.

Carvalho, José Jorge de (2002a). Las Culturas Afroamericanas en Iberoamerica: Lo Negociable y lo Innegociable. En García Canclíni, Néstor (Org.) (2002). Iberoamérica. Diagnóstico y Propuestas para el Desarrollo Cultural (pp. 97-132). Madrid: Santillana, OEI/México.

Carvalho, José Jorge de (2002b). Las Tradiciones Musicales Afroamericanas: De Bienes Comunitarios a Fetiches Transnacionales. Brasilia: Departamento de Antropología, Universidade de Brasília.

Carvalho, José Jorge de (19 Agosto 2011). Comunicación personal, Reunión del proyecto La espiritualidad entre los afrodescendientes peruanos y colombianos: relaciones y resignificaciones. Bogotá: Museo nacional-Ibermuseos.

Cavalli Sforza, Luigi Luca (2007). La evolución de la cultura. Barcelona: editorial Anagrama.

Cruces Villalobos, Francisco (1997). Desbordamientos. Cronotopías en la localidad tardomoderna. Política y Sociedad, 25: 45-58.

Díaz, Cruz, Rodrigo (2008). La celebración de la contingencia y la forma. Sobre la antropología de la performance. Nueva Antropología, XXI (69): 33-59.

Douglas, Mary (1988). Símbolos naturales. Madrid, Alianza. 


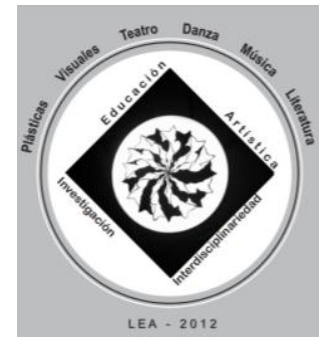

II ENCUENTRO NACIONAL

DE INVESTIGACIÓN, INTERDISCIPLINARIEDAD

Y EDUCACIÓN ARTÍSTICA

8 y 9 de noviembre de 2012.

Universidad Distrital Francisco José de Caldas

Bogotá, Colombia

Durkheim, Emile (1968). Las formas elementales de la vida religiosa. Buenos Aires: Editorial Schapire.

Hall, Stuart (1992). What is this Black? in Black Popular Culture? En Wallace, Michelle y Gina Dent (Eds.) (1992). Black Popular Culture (pp. 21-33). Seattle: Bay Press.

Laignelet, Víctor (2007). El Misterio en los procesos de creación. En Zalamea, Gustavo (Comp.) (2007). Arte y localidad. Modelos para desarmar. Cátedra Manuel Ancizar, II-2006 (pp. 223-239). Bogotá: Universidad Nacional de Colombia.

Losonczy, Ana Marie (1992). Fijación e improvisación de rituales: el chamanismo emberá del Alto Chocó (Colombia). En América Negra, (3): 115-132.

Machado, Caicedo, Martha (2011). La escultura sagrada chocó en el contexto de la memoria de la estética de África y su diáspora: ritual y arte. Bogotá: Universidad Nacional de Colombia.

Maya, Restrepo, Adriana (2010). Malí, Benín, Kongo, tres reinos del África occidental conectados con la historia de Colombia. En Cantor, Burgos, Roberto (2010). Rutas de libertad 500 años de travesía (pp. 107-120). Bogotá: Ministerio de Cultura, Pontificia Universidad Javeriana.

Max- Neef, Manfred, Elizalde, Antonio y Hopenhayn, Martín ([1993] 1998). Desarrollo a Escala Humana. Conceptos, aplicaciones y algunas reflexiones. Barcelona: Editorial Nordan-Comunidad, Icaria Editorial.

Mazo, Margarita (1994). Lament made visible: A study of paramusical elements in Russian lament. In Bell Yung y Joseph Lam (Eds.) Themes and variations: Writings on music in honor of Rulan Chao Pian (pp. 164-212). Cambridge, MA: Harvard University Press.

Miller, Geoffrey (2000) Evolution of human music through sexual selection. En Wallin, Nils, Merker, Björn y Brown, Steven. (Eds.) (2000). The Origins of Music (pp. 329360). Cambridge, MA: MIT Press.

Minaña, Blasco, Carlos (2010). Afinación de las marimbas en la costa Pacífica Colombiana: ¿Un Ejemplo de la Memoria Interválica en Colombia? En Ochoa, Escobar, Juan, Sebastián, Santamaría, Selgado, Carolina y Peñuela, Sevilla, Manuel (Eds.). (2010). Músicas y prácticas sonoras en el litoral pacífico afrocolombiano. (pp. 287-346). Bogotá: Universidad Javeriana.

Oquendo, Diana Catalina (2012, Mayo 22). Alerta por Lenguas. ADN, 20. 


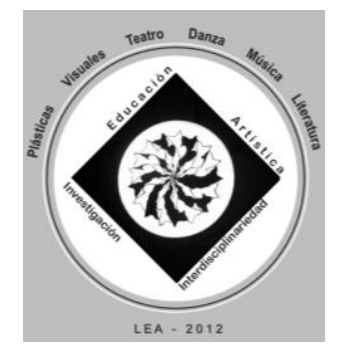

II ENCUENTRO NACIONAL DE INVESTIGACIÓN, INTERDISCIPLINARIEDAD

Y EDUCACIÓN ARTÍSTICA

8 y 9 de noviembre de 2012.

Universidad Distrital Francisco José de Caldas

Bogotá, Colombia

Sánchez, Perea, Yosaira y Luján, Juan David (2012). Visibilización de una estética afrocolombiana a partir del ritual del Lumbalu. (Tesis de pregrado), Licenciatura en Educación Básica con énfasis en Educación Artística, Universidad Distrital Francisco José de Caldas, Bogotá, Colombia.

Schwegler, Armin (1996). “Chi ma' Kongo”: lengua y ritos ancestrales en el Palenque de San Basilio (Colombia). Frankfurt-Madrid: Biblioteca Ibero-Americana.

Rappaport, Roy A. (2001). Ritual y religión en la formación de la humanidad. Madrid: Cambridge University Press.

Reynoso, Carlos (2008). Corrientes teóricas en antropología: Perspectivas desde el Siglo $X X I$. Buenos Aires, Editorial Sb. Versión digital recuperada de http://carlosreynoso.com.ar/ [consultado en Enero 20 de 2013]

Ritzer, George (1993). Teoría sociológica contemporánea. México D.F: Mcgraw-HillInteramericana de España.

Rodney, Walter ([1972] 1982). De cómo Europa subdesarrollo a África. México D.F.: Siglo XXI Editores.

Trouillot, Michel-Rolph (2011). Transformaciones Globales. La antropología y el mundo moderno. Popayán, Bogotá: Universidad del Cauca, CESO-Universidad de los Andes.

Turner, Victor (1969). The ritual process: Structure and anti-structure. Chicago: Aldine.

Turner, Victor ([1967] 1980). La selva de los símbolos. Aspectos del ritual Ndembu. Madrid: Siglo XXI Editores.

Turner, Victor (1988). El proceso ritual. Estructura y antiestructura. Madrid: Alte, Taurus Alfaguara.

Schwegler, Armin (2002a). El vocabulario (ritual) bantú de Cuba (Parts I, II). En Norma Díaz, Ralph Ludwig y Stefan Pfänder (Eds.) (2002) La Romania americana. Procesos lingüísticos en situaciones de contacto (pp. 97-194). Frankfurt: Vervuert / Madrid: Iberoamericana.

Schwegler, Armin (2002b). On the (African) Origins of Palenquero Subject Pronouns. Diachronica, 19 (2): 273-332. 